Kansas State University Libraries

New Prairie Press

\title{
Modeling Potato Psyllid Occurrence Using Sticky Trap Data for the Management of Zebra Chip Disease
}

\author{
William J. Price \\ University of Idaho, bprice@uidaho.edu \\ Erik J. Wenninger \\ University of Idaho, erikw@uidaho.edu \\ Bahman Shafii Ph.D. \\ University of Idaho, bshafii@uidaho.edu
}

Follow this and additional works at: https://newprairiepress.org/agstatconference

Part of the Agriculture Commons, and the Applied Statistics Commons

\section{(c) $(1) \Theta \Theta$}

This work is licensed under a Creative Commons Attribution-Noncommercial-No Derivative Works 4.0 License.

\section{Recommended Citation}

Price, William J.; Wenninger, Erik J.; and Shafii, Bahman Ph.D. (2017). "Modeling Potato Psyllid Occurrence Using Sticky Trap Data for the Management of Zebra Chip Disease," Conference on Applied Statistics in Agriculture. https://doi.org/10.4148/2475-7772.1522

This Event is brought to you for free and open access by the Conferences at New Prairie Press. It has been accepted for inclusion in Conference on Applied Statistics in Agriculture by an authorized administrator of New Prairie Press. For more information, please contact cads@k-state.edu. 


\title{
Modeling Potato Psyllid Occurrence Data Using Sticky Trap Data
}

\section{for the Management of Zebra Chip Disease}

\author{
William J. Price ${ }^{1}$, Erik J. Wenninger ${ }^{2}$, and Bahman Shafii ${ }^{1,2}$
}

\author{
${ }^{1}$ Statistical Programs \\ ${ }^{2}$ Department of Plant, Soil, Entomological Sciences, \\ College of Agricultural and Life Sciences, University of Idaho, Moscow, Idaho
}

Zebra chip is a disease of potato producing striped necrotic patterns that become pronounced when fried, and hence, making products such as potato chips and fries unmarketable. The disease is associated with a bacterium "Candidatus Liberibacter solanacearum" (Lso) and is transmitted by the potato psyllid, Bactericera cockerelli. Due to this pathogen-vector relationship, an important aspect in managing this disease is the modeling and prediction of potato psyllid occurrence. In this study, potato psyllid numbers were monitored regularly around potato fields across the southern Idaho region. This unique data set encompasses psyllid counts, collected by multiple sticky traps, collected at 98 growing sites across the region over 2013, 2014, and 2015 growing seasons. The resulting data are modeled using a modified nonlinear logistic growth function, which accounts for the negative skewness that is inherent in this sticky trap data. The estimated models are subsequently used to compare relevant potato psyllid occurrence parameters between major growing regions of southern Idaho. Comparisons of various trap configurations within each region were also carried out among estimated model parameters. 
23 Results from this modeling effort could help researchers and growers efficiently monitor the

24 psyllid populations and anticipate the potential for future disease outbreaks.

\section{Introduction}

27 Idaho is the leading potato production state with $30 \%$ of national production and $50 \%$ of

28 processed products. Zebra chip, however, could potentially reduce marketable yields in the state.

29 This disease is new to Idaho and was first identified in 2011. It is caused by the bacterium

30 "Candidatus Liberibacter solanacearum" (Lso), which produces striped necrotic patterns in the

31 potato flesh that become pronounced when tubers are fried. This discoloration renders products

32 such as potato chips and fries unmarketable. The bacterium itself is spread by an insect vector,

33 the potato psyllid (Bactericera cockerelli). Management of zebra chip disease concentrates on

34 controlling the potato psyllid vector. Treating fields for psyllid can be costly. In the year 2012, it

35 was estimated that the costs associated with controlling potato psyllids were $\$ 40-\$ 150$ more per

36 acre than the previous year, when the disease in Idaho was first noted.

38 when potato psyllid occurrence is likely to happen during a particular growing season. The work

39 here was carried out to begin addressing the prediction problem for potato growing regions in

40 southern Idaho. Results will be demonstrated using sticky trap data collected as part of a larger

41 multi-site, multi-year monitoring program.

42 


\section{Methods.}

\section{$47 \quad$ Data Description}

Commercial potato fields were monitored over four growing seasons (years 2012-2015)

49 covering three geographic potato growing regions of southern Idaho. As part of this larger

50 project, yellow sticky traps were used to collect adult psyllids, beginning with emergence and

51 continuing through harvest. As a means of gauging sampling efficiency, two different sampling

52 schemes for sticky trap were investigated: Intense sampling - 10 cards around the field at 13-16

53 locations each year; and Light sampling - 4 cards around the field at 77-94 sites/year. Each

54 position had cards facing both towards, and away from, the potato crop. The count data for each

55 trap card side were recorded at weekly intervals.

56 Considerable spatial and temporal variability in the psyllid counts were evident due to

57 changes across sites and years. To mitigate these effects, weekly calendar dates were converted

58 into relevant local degree day measurements using the rectangular method with a lower

59 developmental threshold of $7.1^{\circ} \mathrm{C}$ and a biofix date of 1 January. Additionally, the raw card

60 counts were converted to cumulative proportions over the growing season, relative to the

61 observed maximum for each site-season. Finally, observations from the 4-10 cards per field were

62 averaged for each card side.

63

\section{$64 \quad$ Model and Estimation}

65 Cumulative biological data are often described using an S-shaped logistic form similar to:

$$
\widehat{y}=\frac{1}{1+e^{-B(d d-L)}}
$$


67 For the potato psyllid data, $\widehat{\boldsymbol{y}}$ would be the predicted cumulative proportion, $\boldsymbol{B}$ describes the rate

68 of change, $\boldsymbol{d} \boldsymbol{d}$ are degree days and $\boldsymbol{L}$ is an offset, or in this case, the number of degree days to

69 reach a cumulative proportion of $50 \%$.

70 This basic logistic form, however, assumes a symmetric distribution, while many

71 biological processes are right skewed, showing a rapid initial response that peaks early and then

72 slowly tapers off to zero. The phenomenon is often accounted for in the model by using a log-

73 logistic form, i.e. assuming symmetry on a log scale (e.g. Price et. al, 2012):

$$
\widehat{\boldsymbol{y}}=\frac{1}{1+e^{-B((\ln (d d)-\ln (L)))}}
$$

The potato psyllid data, however, had a distribution which exhibited a left skewedness

77 for this, the degree day scale was reversed through a transformation of variables by subtracting

78 the weekly degree day values from the observed maximum degree day within each site-year,

$79 \operatorname{Max}_{d d}$. This transformation essentially flips the distribution about the horizontal axis, converting 80 a left skewed form to a right skewed form, which is more amendable to the log-logistic model.

81 The above conversion is accomplished by rewriting (2) as:

$$
\widehat{y}=\frac{1}{1+e^{-B((\ln (\operatorname{Max} d d-d d))-(\ln (\operatorname{Max} d d-L)))}} .
$$

84 predictions interpretable as weekly occurrence throughout the season. In this form, parameter $\boldsymbol{L}$ 85 represents an inflection point, or the degree day at which maximum infestation will occur. 
88 with $\pi$ estimated by (3) and $\phi$ as an additional dispersion parameter. Spatial - temporal variability

89 due to site-years was accounted for by assuming a random effect, $\varepsilon$, on parameter $\boldsymbol{L}$, where $\varepsilon \sim$

90 normal $\left(0, \sigma^{2}\right)$. Models were initially estimated separately for trap card sides as well as the

91 different growing regions. Following model assessment, dummy variable regression techniques

92 were used to compare parameter estimates between the two card sides or growing regions. All

93 estimation and graphics were carried out using SAS 9.4 (2012).

94

95

\section{Demonstration}

96

97 Only two of the three potato growing regions, the Treasure Valley and the Magic Valley

98 (Figure 1), had sufficient data for modeling.

99

100

101

102

103

104

105

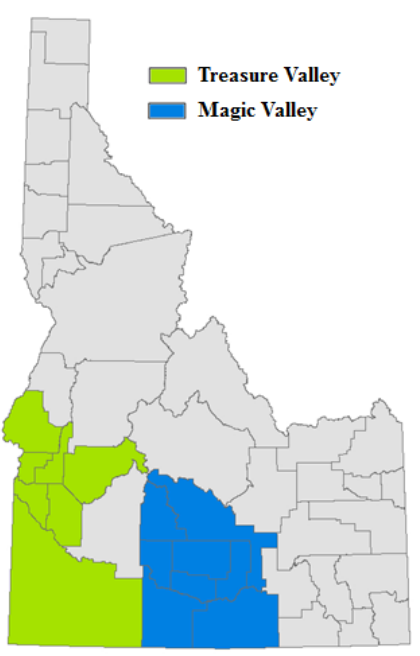

106

107

Figure 1. The Treasure Valley and Magic Valley Potato growing regions of Idaho.

108 
109 While full analysis of both sampling schemes was carried out, this demonstration will

110 concentrate on the intense sampling scheme (10 traps/site) data.

111 Models were estimated separately across all site-years for the two trap side categories

112 (inward and outward from the potato field) within each growing region. The estimated curves fit

113 the data well (e.g. Figure 2: Treasure Valley) and all parameter estimates were significant (Tables

1141 and 2). In the Treasure Valley, psyllid occurrence showed an inflection point of about 1800

115 degree days, while that for the Magic Valley was about 1500.

116

117

118

119

120

121

122

123

124

125

126

127

128

in the Treasure Valley. Panels represent data from sticky trap cards facing away from (A) and

129

towards (B) the potato fields.

130

131

132

133

134 
Table 1. Logistic curve parameter estimates for the cumulative proportion of potato psyllid capture in the Treasure Valley. Rows represent estimates from sticky trap cards facing away

137 from (1) and towards (2) the potato fields.

\section{Treasure Valley}

\begin{tabular}{|c|c|c|c|c|}
\hline Card Side & Parameter & Estimate & $\begin{array}{c}\text { Standard } \\
\text { Error }\end{array}$ & $\operatorname{Pr}>|\mathbf{t}|$ \\
\hline \hline \multirow{2}{*}{$\mathbf{1}$} & $\boldsymbol{B}$ & 4.1 & 0.5 & $<.0001$ \\
\cline { 2 - 5 } & $\boldsymbol{L}$ & 1798.2 & 42.1 & $<.0001$ \\
\hline \multirow{2}{*}{$\mathbf{2}$} & $\boldsymbol{B}$ & 3.6 & 0.4 & $<.0001$ \\
\cline { 2 - 5 } & $\boldsymbol{L}$ & 1751.3 & 45.4 & $<.0001$ \\
\hline
\end{tabular}

Table 2. Logistic curve parameter estimates for the cumulative proportion of potato psyllid

142 (1) and towards (2) the potato fields.

\section{Magic Valley}

\begin{tabular}{|c|c|r|r|c|}
\hline Card Side & Parameter & Estimate & $\begin{array}{c}\text { Standard } \\
\text { Error }\end{array}$ & $\operatorname{Pr}>|\mathbf{t}|$ \\
\hline \hline \multirow{2}{*}{$\mathbf{1}$} & $\boldsymbol{B}$ & 3.7 & 0.6 & $<.0001$ \\
\cline { 2 - 5 } & $\boldsymbol{L}$ & 1520.0 & 97.8 & $<.0001$ \\
\hline \multirow{2}{*}{$\mathbf{2}$} & $\boldsymbol{B}$ & 3.5 & 0.5 & $<.0001$ \\
\cline { 2 - 5 } & $\boldsymbol{L}$ & 1540.0 & 102.3 & $<.0001$ \\
\hline
\end{tabular}

Within each growing region, it was of interest to compare the two card sides in order to 
147 (Figure 3; Table 3). No significant differences in the trap side models were found in either

148 growing region. Trapping data were considered to be equivalent from inward and outward facing

149 sticky traps.

150

151

152

153

154

155

156

157

158

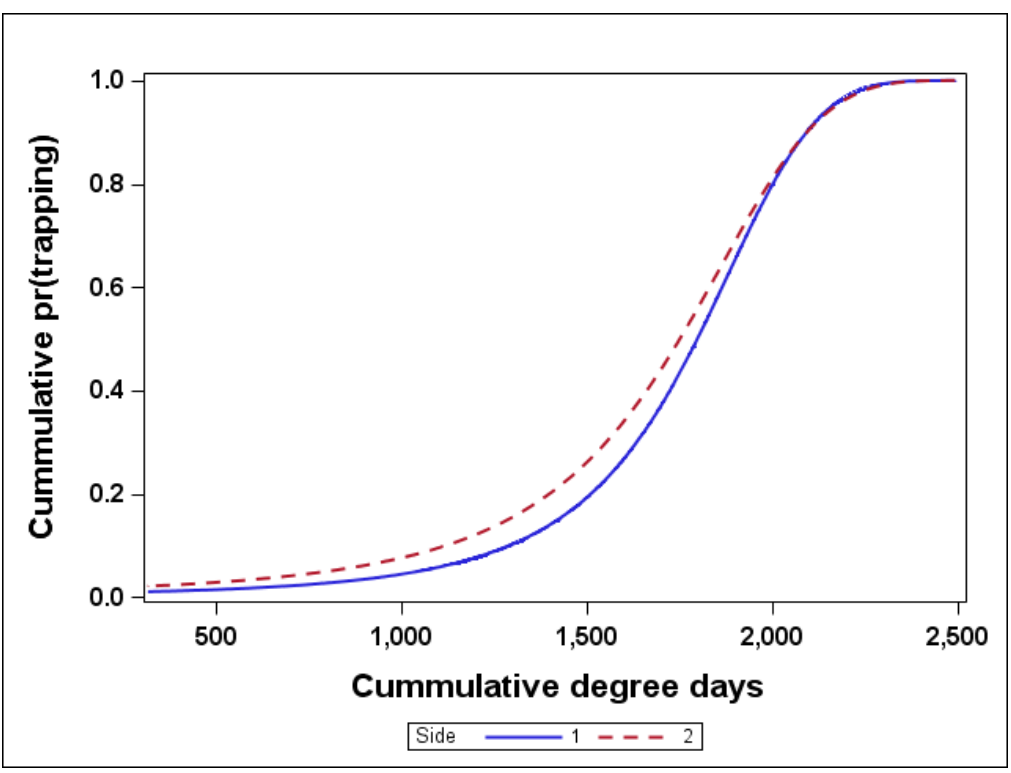

161

Figure 3. The predicted left skewed logistic curves for the Treasure Valley 


Treasure Valley
\begin{tabular}{|c|c|}
\hline Contrast & Pr $>\mathbf{F}$ \\
\hline \hline Lines & 0.5329 \\
\hline Rates $(\boldsymbol{B})$ & 0.5137 \\
\hline Onset $(\boldsymbol{L})$ & 0.4641 \\
\hline
\end{tabular}

\begin{tabular}{|c|c|}
\multicolumn{1}{c}{ Magic Valley } \\
\begin{tabular}{|c|c|}
\hline Contrast & Pr $>\mathbf{F}$ \\
\hline \hline Lines & 0.9428 \\
\hline Rates $(\boldsymbol{B})$ & 0.7475 \\
\hline Onset $(\boldsymbol{L})$ & 0.8278 \\
\hline
\end{tabular}
\end{tabular}

174 Given these non-significant results, the side data were subsequently pooled to provide a "total"

175 relative count response per card and a single model was re-estimated for each growing region

176 (Figure 4, Table 4).

177

178

179

180

181

182
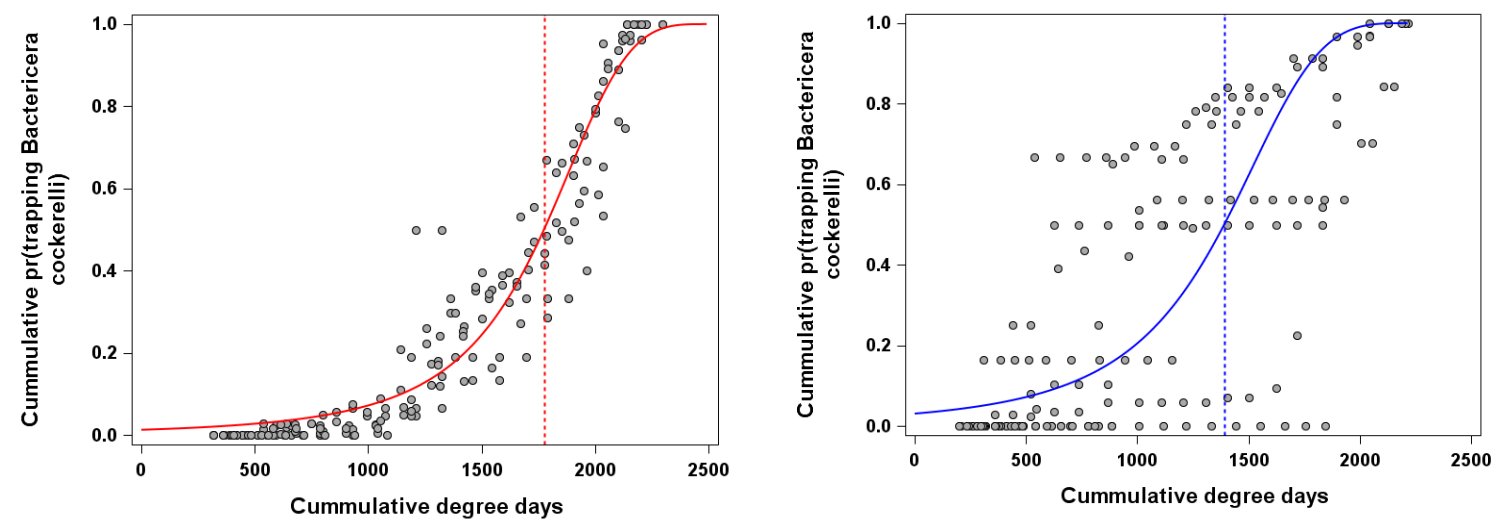

Figure 4. The estimated total psyllid count logistic curve fits for (A Treasure Valley and b) Magic Valley. 
Table 4. Parameter estimates for the logistic models predicting total psyllid catch on sticky traps in the treasure and Magic Valley growing regions.

\section{Treasure Valley}

\begin{tabular}{|c|r|r|c|}
\hline Parameter & Estimate & $\begin{array}{c}\text { Standard } \\
\text { Error }\end{array}$ & $\operatorname{Pr}>|\mathbf{t}|$ \\
\hline \hline $\boldsymbol{B}$ & 3.5 & 0.1 & $<.0001$ \\
\hline $\boldsymbol{L}$ & 1775.2 & 77.5 & $<.0001$ \\
\hline
\end{tabular}

Magic Valley

203 While the results for the Treasure Valley were similar to previous results, those for the Magic

204 Valley differed slightly from the initial fits. The Magic Valley data were more variable and the 205 estimated inflection point, $L$, was smaller than the previous estimates.

206 The de-cumulated model form is more interpretable for practitioners, showing the rate of 207 change in psyllid occurrence throughout the growing season. The inflection point (parameter $L$ ) 208 in this form indicates the point in time of peak infestation. The two estimated regional models 
were transformed in this manner for reporting (Figure 5). Here, the faster infestation rate of the Magic Valley is clearly evident.

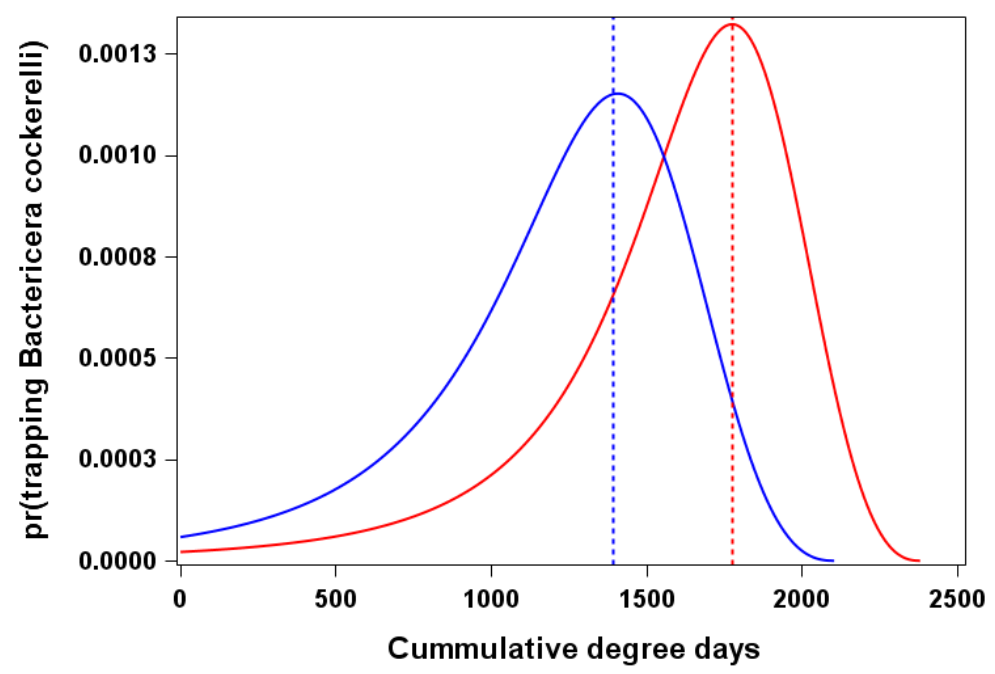

Figure 5. The predicted de-cumulated psyllid occurrence models for the Treasure Valley (red) and Magic Valley (blue) potato growing regions.

As a means of comparing psyllid infestations across the two growing regions, a second full dummy variable model incorporating the two regions was fit and contrasts comparing the two curves, as well as the individual parameter estimates, were carried out (Table 5). While the Magic Valley indicated a lower number of degree days for peak infestation, the difference in the full model assessment was non-significant. This lack of significance is likely due to the higher level of variability in the Magic Valley data. Further discrimination and assessment of the sites within the Magic Valley region may be necessary to diagnose the underlying source of the variability, which may in turn lead to a more precise model estimation. 
232 Table 5. Full dummy variable contrasts assessing coincidence of lines and individual parameters

233 of the estimated logistic curve fits for psyllid occurrence data in the Treasure and Magic Valley

234 potato growing regions.

\begin{tabular}{|c|c|}
\hline Contrast & $\operatorname{Pr}>\mathbf{F}$ \\
\hline \hline Lines & 0.6277 \\
\hline Rates $(\boldsymbol{B})$ & 0.8977 \\
\hline Onset $(\boldsymbol{L})$ & 0.3672 \\
\hline
\end{tabular}

\section{Concluding Remarks}

Nonlinear modeling of sticky trap data provides a useful tool for monitoring and managing

244 potato psyllid and the associated zebra chip disease in Idaho. For this type of occurrence data,

245 however, the left skewed nature of the count data over time is not amendable to standard

246 nonlinear logistic model analysis. A transformation (reversal) of the regressor axis (cumulative

247 degree days) may be used as a corrective measure, producing a right skewed data pattern that can

248 be modeled using standard nonlinear logistic techniques.

249 Sticky trap monitoring data collected over four years and multiple sites across southern

250 Idaho were modeled in this manner. Models were estimated separately for different trap sides

251 within two major potato growing regions. Comparison of the estimated models indicated no

252 significant differences in inward or outward facing trap sides. Further assessment of the models 
253 was then carried out for similarities of the growing regions. Although the Magic Valley model

254 estimates suggested that peak psyllid infestation may occur earlier in the season relative to the

255 Treasure Valley, no significant differences were found between the predicted models of each

256 region. The higher variability observed in the Magic Valley data, however, may have masked

257 this potential difference. While the source of this higher variability is not yet identified, doing so

258 will be desirable to obtain a more precise estimation of the model for that region. The estimated

259 models reported in this study represent an initial step towards predicting the occurrence of potato

260 psyllid infestation, and by extension, zebra chip disease. Before implementing these models,

261 however, further work will be required to validate their reliability.

262

263

\section{References}

264

265 Pinheiro, J. C and D. M. Bates. 1995. Approximations to the Log-Likelihood

266 Function in the Nonlinear Mixed-Effects Model. Journal of

267 Computational and Graphical Statistics 4, 1:12-35.

268

269 Price, W. J., B. Shafii, and S. S. Seefeldt. 2012. Estimation of Dose-Response

270 Models for Discrete and Continuous Data in Weed Science. Weed

271 Technology, 26:587-601.

272

273 SAS Institute Inc. 2012. SAS OnlineDoc® 9.4. Cary, NC: SAS Institute Inc.

274 